\title{
A General Process for Synthesis of Enantiopure Sulfinates and Sulfoxides
}

$$
\begin{aligned}
& \text { (-)-Quinine } \frac{\text { 1) } \mathrm{SOCl}_{2}-\mathrm{Et}_{3} \mathrm{~N}}{\text { 2) } \mathrm{RMgCl} \text { or } \operatorname{ArAlEt}_{2}, \mathrm{THF},-78{ }^{\circ} \mathrm{C}} \\
& \text { 3) } \mathrm{R}^{\prime} \mathrm{MgCl} \text {, THF } \\
& \text { (-)-Quinine }
\end{aligned}
$$
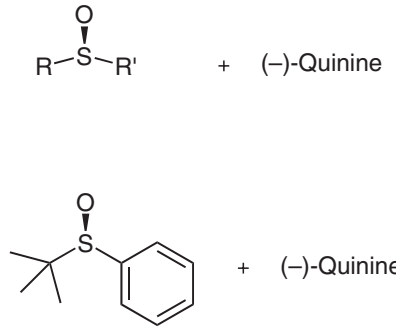

(-)-Quinine
Significance: Among various methods, developed for the synthesis of enantiopure sulfoxides, the use of naturally occurring quinine as a chiral auxiliary has a lot of advantages: all the reagents are easily available, cheap, the one-pot procedure is very simple to perform and the auxiliary can be readily recovered. The procedure gives in all reported cases practically enantiopure products.
Comment: In most syntheses of enantiopure sulfoxides from organometallic species, the enantioselectivity is based on the difference between two $\mathrm{S}-\mathrm{Y}(\mathrm{Y}=\mathrm{O}$ or $\mathrm{N})$ enantiotopic bonds. The originality of this approach relays on the formation of a non-covalent $\mathrm{S}-\mathrm{N}$ bond as enantiotopic for an easily available quinine derivate, that allowed practically complete stereocontrol in the reaction with organometallic reagents. 